\title{
a.JPE $\mathrm{s}$
}

\section{Reciprocity and Resources}

\author{
ELIZABETH FENTON \\ University of Otago
}

\begin{abstract}
Reciprocity has been deployed as the moral concept underpinning an obligation to ensure that health care workers (HCW) who work during a pandemic have access to essential goods, such as personal protective equipment (PPE), and as a principle for giving priority to HCW for scarce resources, such as intensive care beds or ventilators. In this paper I examine the concept of reciprocity, arguing that it is best understood as a form of fairness, or "fair return for services rendered." This interpretation works well in explaining our obligation to provide HCW with PPE and other risk-mitigation resources, but I give reasons to suggest that it does not support an obligation to prioritize HCW for scarce medical interventions.
\end{abstract}

Keywords: reciprocity, personal protective equipment (PPE), COVID-19, health care workers (HCWs), priority.

\section{Introduction}

The COVID-19 pandemic, which began in 2020 and is ongoing at the time of this writing, is the latest public health crisis to compel re-examination of ethical questions about the duty of health-care workers (HCWs) to accept increased risks of exposure to infectious disease when providing care to patients and what is owed to HCWs when they take on those risks. Often these obligations are couched in terms of the concept of reciprocity. In this latest crisis, two candidates have emerged as commensurate reciprocal returns for the risks HCWs assume: personal protective equipment (PPE) and priority access to limited, or scarce, treatment interventions, such as intensive-care unit (ICU) beds and ventilators. This paper examines the concept of reciprocity to determine whether it justifies these returns. The key question is whether it is justifiable to provide PPE or

Contact: Elizabeth Fenton <elizabeth.fenton@otago.ac.nz> 
priority access to HCWs on grounds of reciprocity, leaving open the possibility that these returns might be justified on other grounds.

Moral obligations of reciprocity for HCWs and pandemics arise in three ways. First, reciprocity is claimed as a moral foundation for the professional obligation of HCWs to continue to work, including in situtations of heightened risk. This 'social contract view' holds that HCWs-or, more specifically, physicianshave a duty to treat or to care, even at risk to themselves, in exchange for the benefits society accords them as members of their profession, such as subsidised education, self-regulation, monopolistic privileges, and status (Arras 1988; Malm et al. 2008; Reid 2005). Second, reciprocity is cited as the moral foundation for societal, governmental, or institutional obligations to provide essential goods to HCWs that will mitigate the heightened risks they assume when continuing to work during a pandemic. In the wake of the 2003 SARS epidemic, Ezekiel Emanuel wrote that if HCWs have a duty to treat under these circumstances, then health-care administrators and senior physicians have a 'correlative duty' to develop and deploy equipment to maximize their safety (2003). Angus Dawson argues that while society provides benefits and incentives to HCWs to ensure they come to work when needed, it also incurs 'reciprocal obligations' to ensure a safe working environment (2016). Where these reciprocal obligations are not met, and risks not adequately mitigated, the professional obligations of HCW to assume those risks are weakened. In the context of the COVID-19 pandemic, in which inadequate PPE for HCWs has been a significant concern, Udo Schuklenk argues that the duty to treat is dependent or contingent on the provision of adequate PPE. Where able governments have actively starved health-care systems of resources, including those necessary to protect staff during a pandemic, HCW bear no professional obligations to take on the heightened risks of caring for infected patients (2020). Praising HCWs for their heroic efforts in situations of heightened risk obscures the extent to which these governments have failed to meet their reciprocal obligations (Cox 2020; Reid 2005).

Third, reciprocity is deployed as a prioritization principle for scarce resources. Some argue, for example, that just as reciprocity justifies preferential allocation of organs to past donors, or priority to military veterans, an analogous justification is available for giving HCWs who assume additional risks during a pandemic priority access to limited medical interventions (Persad, Wertheimer, and Emanuel 2009). This argument has been advanced for ICU beds and ventilators during the COVID-19 pandemic (Jecker, Wrightmas, and Diekema 2020; Aulisio and May 2020; Emanuel et al. 2020; White and Lo 2020). As a pragmatic strategy, prioritizing limited treatment resources for HCWs might incentivize people to come to work and ensure that those who get sick 
can be treated and return to the workforce. However, while the pragmatic strategy recognizes the instrumental value of HCWs and prioritizes them based on their utility, invoking reciprocity is intended to provide a noninstrumental basis for giving priority to HCWs for limited resources. Reciprocity asks not whether priority will maximize a person's utility but whether it is what justice requires (Faulconer 2020).

These three uses of reciprocity are closely related. If HCWs have a duty to treat-whether grounded in reciprocity or some other justification (such as their specialised skills or voluntary assumption of the risks of their profession (Johnson and Butcher 2020)) - then they are entitled to expect that they will be supported in their duty as much as possible. The key question of this paper is what is owed to HCWs in return - that is, as a matter of reciprocity - for their fulfilling this duty. Recognizing that the assumption of increased risk, coupled with the demands of caring for those who are ill, puts HCWs in a position of increased responsibility and stress, along with many others who contribute to the functioning of health-care systems during an emergency, reciprocity requires providing those workers with additional support (National Ethics Advisory Committee 2007). What is needed is an account of reciprocity that will distinguish between what additional support is owed to HCWs as a matter of justice and what might be useful, or desirable, to provide.

Section 2 develops an account of reciprocity as a form of fairness and argues that, in the context of public goods that are beneficial to all, such as the protection and promotion of public health, reciprocity generates social and political obligations that contribute to the maintenance of those goods. Sections 3 and 4 examine two candidates for answering the question of what is owed to HCWs, as a matter of reciprocity, for their assumption of increased risk during a pandemic. These are PPE and priority for limited treatment interventions, such as ventilators or ICU beds. Section 3 argues that the provision of adequate PPE is an obligation generated by the norms of reciprocity and fairness. Section 4 presents reasons for resisting the view that giving HCWs priority for limited treatment interventions is an obligation of reciprocity. One reason is that priority for these interventions does not straightforwardly meet the criteria for a fair return, criteria elaborated on in the account of reciprocity given in section 2. A second reason is that where sufficient measures have been taken to reduce an HCW's ex ante risk (that is, their risk of becoming infected) through PPE, it is not clear that there is a further obligation, grounded in reciprocity, to reduce their ex post risk (that is, their risk of dying if they become infected) over any other candidate for the resource. Further reasons relate to competing considerations of justice that enter into prioritization of scarce treatment interventions, considerations such as saving the most lives (New York State Taskforce 2015: 45). 


\section{Reciprocity}

In its canonical form, reciprocity is about 'how to respond to people who have done us a favor' (Schmidtz 2005: 459). The capacity to reciprocate is important, because reciprocity is 'at the core of a viable community' (462). As a norm (that 'good be given for good received'), Lawrence Becker argues that not only is reciprocity a brute fact of everyday moral life, the disposition to reciprocate is a moral virtue that should be cultivated. Reciprocal relationships are 'an essential part of the social conditions necessary for human flourishing as human beings' (2005: 31). In A Theory of Justice, Rawls argues that reciprocity, 'a tendency to answer in kind', is a deep psychological fact, without which 'our nature would be very different and fruitful social cooperation fragile if not impossible" (1971: 494-95).

Some have reacted with concern to the idea that reciprocity be conceived as central to moral relations, since it seems to imply that only those who are capable of giving 'good' are entitled to receive good in return. Allen Buchanan, for example, is concerned about the implications for distributive justice if it is grounded in the notion that 'only those who do (or at least can) make a contribution to the cooperative surplus have rights to social resources' (1990: 230). What Buchanan calls 'justice as reciprocity' is disturbing by virtue of its implications for those who cannot contribute (such as the severely disabled, children, and the elderly) but who are (and should) nevertheless be considered within the scope of justice. Justice should not be equivalent to a mantra of 'you get out what you put in'.

Becker, arguing that the purpose of reciprocity is to 'sustain mutually advantageous exchanges' (1986: 112), might seem to fall foul of Buchanan's concern that reciprocity has no place in a theory of justice that promotes the rights and entitlements of all, rather than those with whom exchange is mutually advantageous. Yet Becker maintains that a developed conception of reciprocity requires significant benefits for those excluded from Buchanan's definition of justice as reciprocity - in particular, the disabled (2005: 18). One of his key insights is that the concern that only those who can contribute are entitled to benefits in return reflects an oversimplification of the concept of reciprocity. In this concern, reciprocity is characterised in terms of direct titfor-tat exchanges, in which benefits given and returned must be roughly equivalent. Becker argues instead that reciprocity is as much about generalised and indirect acts of contribution and return as it is about one-to-one exchanges: 'Some of us give money to Oxfam, in the devout hope of never having to use its services, and what comes around to us reciprocally [. . .] is something so remote from our contribution that we are unlikely to recognize it as reciprocity for anything in particular' (2005: 20). Therefore, reciprocity, as a principle of justice, is more closely aligned with 'what goes around comes around' than 
it is with 'you get out what you put in'. This conception sustains a system in which the disabled, and the disadvantaged more generally, are supported through a robust social commitment to human flourishing from which all will, in some form or other, benefit.

Becker's treatment of reciprocity is one of the most robust in the literature and distinctive for specifying in detail what will count as a reciprocal return for good (and bad) received. In general terms, a reciprocal return must be commensurate or 'appropriate as to type and quantity' (1986: 106). Appropriateness is ultimately determined by whether a return satisfies the goal of reciprocity, which is to maintain 'the sort of social equilibrium that makes productive social exchange possible' (Becker 1986: 106). Maintaining this equilibrium requires reciprocal exchanges that are bounded in two important ways. First, a return must be fitting, which means it must be something that those to whom we are reciprocating will perceive as a return, and as a good. Second, it must be proportional, where proportionality concerns the sufficiency of the return relative to the good received. The purpose of the condition of proportionality is to ensure that reciprocity produces a 'balanced' exchange. ${ }^{1}$ These two conditions are critical to an account of reciprocity because they set limits on what is required in terms of a return.

Of particular interest for this paper is Becker's treatment of fittingness and proportionality in the context of collective or 'corporately produced goods' that is, goods that give one benefits beyond what can be returned by individuals, either in terms of the quantity or the sum total of the sacrifices made to produce said benefits. In the case of these goods (which include the maintenance of public health and safety), Becker argues that a fitting return amounts to reciprocal participation in the institution that produces or maintains the good (which might be on a small scale, such as a blood bank, or a large scale, such as a national government), and a proportional return is a proportional contribution or level of participation. Reciprocity for the benefits of these collective goods requires that beneficiaries contribute their 'fair share' to the collective institutions they want to sustain, where a fair share is 'a fitting and proportional return for the benefits provided by social institutions we want to sustain through reciprocity' (1986: 115). ${ }^{2}$

1. Becker rejects the notion that proportionality requires equality in the benefits on each side of a reciprocal exchange, arguing instead that a return should be considered proportional (and the exchange balanced) when it requires an equal marginal sacrifice from both parties, where sacrifice is understood in terms of comprehensive economic and noneconomic opportunity costs (Becker 1986; Becker 2005).

2. As beneficiaries, fair share is 'scaled to the benefits we actually receive, and then adjusted in terms of our ability to repay' (1986: 126). 
An outstanding question for an account of reciprocity is when, and why, obligations to reciprocate arise. One possible answer, suggested by Becker, is that reciprocity is required when it is necessary to sustain social practices, transactions, and institutions that are themselves crucial for human well-being or the generation of 'primary human goods', or goods that everyone needs, regardless of whatever else they want (1986, 132). Becker is particularly concerned about the role of reciprocity in nonvoluntary exchanges - that is, exchanges in which benefits are received rather than chosen, such as the benefits of clean air or freedom from infectious disease (1986: 73). This is a concern about the scope of reciprocity: whether people should be disposed to reciprocate only for the goods they have voluntarily and explicitly accepted, or whether people should be disposed to reciprocate for all the goods they have received, including those, such as collective or public goods, that one cannot, without significant effort, reject. Becker's answer is that a dispostion to reciprocate, or to be required to reciprocate, is a powerful means of sustaining the production of these collective, public, and primary goods, goods that are needed 'before we can ask for them or accept them contractually' (1986: 125). Dependence on such goods, the benefits of which are received though may not be explicitly accepted, means that people need, in turn, 'the social structures or personal virtues in others that will sustain the production of such goods' (1986: 125). Reciprocity creates such structures and is such a virtue.

Becker's argument for reciprocity for benefits received and not merely accepted overlaps with that aspect of political philosophy concerning the source of political obligations. One source, proposed by H. L. A. Hart, and later John Rawls, is the principle of fairness or fair play, according to which, in the context of schemes in which cooperation generates benefits, all those who benefit have an obligation to contribute (Hart 1955; Rawls 1971). Some have rejected this principle on the grounds that it permits bestowing unwanted and unaskedfor benefits and then demanding reciprocal payment. As Robert Nozick argues, 'One cannot, whatever one's purposes, just act so as to give people benefits and then demand (or seize) payment. Nor can a group of persons do this' (1974: 95). On Nozick's view, only individual consent generates binding obligations on an individual to cooperate in or contribute to a scheme or make return for benefits received. One problem with this argument is that for some goods, it is not possible voluntarily to accept or consent to them, because it is not possible voluntarily to reject or opt out of them. Included in this category are what Richard Arneson calls pure public goods, or goods that are consumed by everyone in the same amount (such as national defense, freedom from epidemic disease, or the rule of law) (1982). For these goods, mere receipt of the benefits is sufficient to generate an obligation on the part of the recipient to contribute to or cooperate with the scheme, since individual consent is, if not impossible, certainly 
impractical. For collective goods, or those from which it is not feasible to exclude anyone but which an individual can still choose whether or not to consume or accept, voluntary acceptance of the benefits (which implies a form of consent) is sufficient to generate an obligation on the recipient. Arneson's argument is that the principle of fairness, applied only to these categories of public goods, and with other provisos about the fair distribution of benefits and burdens, can stand against Nozick's criticism. Moreover, the principle protects against free riders in the context of collective goods, where it is not possible to exclude anyone from consuming the good, including those who have not contributed (for reasons of choice rather than ability) to the costs of producing it. ${ }^{3}$ Similarly, George Klosko argues that the principle of fairness generates obligations on the recipients of goods that are 'indispensable to the welfare of the community', or what he calls 'presumptive public goods' (1987: 246-47). These obligations are owed by the recipients of the benefits to 'their fellow citizens who provide them' (Klosko 2020: 344). For the purposes of this discussion, the key point of both Arneson's and Klosko's defenses of the principle of fairness, applied to pure public and collective goods or presumptive public goods, is that the principle justifies obigations of reciprocity: '[W]e owe a fair return for services rendered to those who supply the services' (Arneson 1982: 633). Becker further specifies that a fair return will be one that is commensurate with the benefits received - that is, one that is fitting and proportional.

The next section argues that this conception of reciprocity as a form of fairness applies in the context of the provision of specific support during a public health emergency to HCWs who assume higher levels of risk in order to provide essential services. Providing such support (in particular measures to mitigate risk, such as PPE) is a requirement of justice grounded in the principles of reciprocity and fairness. It might also be required for other reasons, including legal employment requirements and pragmatic reasons, but it is first and foremost a requirement of justice.

\section{Obligations of Reciprocity to HCWs}

The principle of fairness grounds obligations of reciprocity. When someone (or a group or institution) provides a good, and the maintenance of that good depends

3. The coercion of free riders to pay their share under the principle of fairness is no different, Arneson argues, to the rules of private property against those who would prefer the benefits of a free-use system. Just as a system of private property limits the extent to which someone can benefit from the work of others, without having worked themselves, so the (revised) principle of fairness "encapsulates the moral conviction that it is legitimate to frustrate the desire to benefit from the pains of others when one has no right to the fruit of their pains" (Arneson 1982: 628). 
on contributions from all who benefit, then the beneficiaries are obligated to do their fair share to maintain it. Using Becker's interpretation of fair shares, the beneficiaries owe a fitting and proportional return for the good received. The argument that follows assumes that a functioning public health-care system (one that is publicly funded and universally accessible) is a presumptive public good following Klosko's definition (i.e., a good that is indispensable to the welfare of the community). It is also a collective good. While the direct benefits of such a system go to those who use it, its indirect benefits are enjoyed by everyone, since everyone is a potential user. ${ }^{4}$ These indirect benefits are especially evident during a public health emergency, when it is clear that all members of a population or community are vulnerable to a greater or lesser extent and that an end to the emergency depends, at least partially, on the robustness of the health system.

Assuming that a functioning public health-care system is a presumptive public or collective good and that all of society are (either directly or indirectly) beneficiaries of that system, it follows that all have obligations of justice, grounded in principles of reciprocity and fairness, to give a fitting and proportional return to those who provide the benefits of that good. Since HCWs are critical providers of the goods of a functioning public health-care system, they are owed fitting and proportional return for the services they provide. The grounds of reciprocity can be further specified by arguing that HCWs are owed reciprocal goods in the context of a pandemic because they assume increased risks in order to contribute to the public good. This specification implies that such goods are also owed to non-HCWs who are critical to a functioning public health-care system and who assume increased risks, as well as those who assume increased risks to provide other essential public goods. I will discuss these implications below.

This argument explains why reciprocal returns are owed to HCWs. The key question that follows is what counts as a reciprocal return in this context. The two candidates under consideration here are PPE and priority access to limited treatment interventions, which will be considered in turn.

Obligations of reciprocity require that fair (fitting and proportional) return be made for services rendered. Fitting and proportional return for the services of HCWs to the functioning of the public health-care system during a pandemic must include adequate protective resources in order for HCWs to do their jobs as safely and effectively as possible. A fitting return is one that is good for the recipient and is percevied by the recipient both as a good and as a return (Becker 1986: 107). PPE meets these conditions. First, PPE is clearly a good for those, particularly but not only HCWs, who are at increased risk, because it confers a

4. The fact that everyone benefits, at least indirectly, is what makes the good 'inexcludable' (i.e., an individual cannot be excluded from the benefits, even if they can choose whether or not to consume the good directly). 
protective benefit. Second, it is perceived as a good by HCWs because it is valuable under the specific circumstances of the increased risk they assume by coming to work. Finally, it is perceived as a return because it is relevant to the services rendered under those specific circumstances. As Becker notes, when the purpose of a reciprocal exchange is to sustain a particular practice or institution (in this case, ensuring HCWs can work safely during a pandemic), a fitting return must be relevant to that practice or institution. Giving HCWs gold stars when they come to work during a pandemic would not be relevant to their specific circumstances of bearing heightened risk. PPE, on the other hand, is relevant to that specific circumstance and is therefore a fitting return. Similarly, PPE is a proportional return because it is proportional to the risk incurred: higher risk demands higher levels of protection. Where the provision of PPE and other protective measures matches the risk incurred, it produces a 'balanced' exchange: increased protection for increased risk. PPE is therefore a proportional return.

From this analysis it seems clear that PPE meets the conditions of a reciprocal return. It is important to note, however, that the obligation to provide PPE to HCWs is often expressed as a reciprocal obligation to the duty to treat: if HCWs have a duty to treat and meeting that duty places them at increased risk, then there is a reciprocal obligation to mitigate that risk with PPE. So expressed, this argment suggests that it is not only the exposure to increased risk that grounds the reciprocal obligations but the exposure to risk in the course of fulfilling the duty to treat. Therefore, there are special obligations to HCWs to reduce their ex ante risk (the risk of infection) because they are bound by a duty to treat. Exposure to increased risk is therefore a necessary but not a sufficient condition for a reciprocal obligation to provide PPE.

The problem with this argument is that it limits the scope of the reciprocal obligation. The interpretation of reciprocity outlined above implies that all those who provide benefits or services necessary for human well-being (that is, presumptive public goods) are owed reciprocal returns, which implies all essential workers exposed to increased risk in the course of providing essential services during a pandemic, not only HCWs, are owed PPE as a matter of reciprocity. So the argument for PPE as a reciprocal return needs to be broader in scope - that is, not limited to $\mathrm{HCWs}$ - to reflect the interpretation of reciprocity adopted above.

\section{Reciprocity and Limited Treatment Interventions}

The second candidate for a reciprocal return to HCWs for the increased risk they assume is priority access to limited treatment interventions - in particular, ICU beds or ventilators. A number of scholars have argued that priority access to these interventions is owed to HCWs as a matter of reciprocity. Mark Aulisio 
and Thomas May, for example, argue for priority access by analogy with the health and other benefits given to active-duty military personel, or to police and fire fighters after $9 / 11$, as recognition of societal duties of reciprocity. Prioritizing HCWs for scarce medical resources 'would seem to be the least we could do for these "first responders" on the frontlines of the SARS-CoV-2 battle' (2020).

This analogy is problematic, however. The health and other benefits provided to military and emergency personel come out of a general pool of resources distributed across the community. All of society, as direct and indirect beneficiaries of their services, make fair-share contributions to this pool by paying taxes and engaging in the democratic processes that can support the making of fair returns to the people who delivered benefits. In the case of priority for scarce treatment resources, however, not all contribute to the return given to HCWsin fact, the cost of this return is borne only by one specific group: those also competing for the scarce resource. A return is proportional when it produces a 'balanced' exchange, which is determined by looking both at what it costs each party to give and what benefits they receive. We first have to ask, Who are the parties to the exchange in this case? On one side, there are sick HCWs who have assumed increased risk in order to provide a presumptive public benefit. They have given their services and the beneficiaries of those services (the community at large) want to give priority for treatment in return. But this return is not the community's to give. In the case of priority for ICU beds or ventilators, the other party to the exchange is the group of other patients who are also waiting for the necessary care. The return at issue is surely theirs to give (i.e., they are the ones making the sacrifice). So HCWs benefit from the return, but those who are making the return (or determining that priority is fair return) are not paying its costs. No balanced exchange is possible here, since the party making the sacrifice (other patients awaiting treatment) are not the ones from whom the return is owed. It is not a fair return for services rendered if it places a disproportionate share of the burden of making that return on only some beneficiaries. Priority to HCWs for scarce treatment resources is not a proportional return.

We might also question whether priority for ICU beds or ventilators meets the condition of fittingness. A fitting return must be a good for the recipient, but ICU care does not always meet this condition, as it can cause more harms than benefits (Ballantyne et al. 2020). Scarce goods are often overvalued, which might affect how the 'good' of ICU or ventilator care is perceived. For these reasons, priority for limited treatment interventions is not clearly a fitting return either.

Possibly these challenges to the fittingness and proportionality of priorty access as a reciprocal return are not convincing. In particular, they may not be convincing in the face of an apparently strong moral intuition that HCWs should be given some priority in accessing limited treatment interventions because of the services they have provided and the risks they have assumed to do so. The 
strength of this intuition might underpin the widely adopted proposal advanced by White and Lo that the priority scores for HCWs for ventilators or ICU admission be adjusted to reflect their status as HCWs (2020). It may also be elicited by considering a tiebreaker case, where two candidates for ICU or ventilator care are equally matched on all criteria, and one candidate is an HCW who contracted the infection in the course of their work. In such a scenario, it seems reasonable to think that the HCW deserves at least some priority. This suggests that, as a matter of reciprocity, the ex ante risk of HCWs must be reduced through the provision of adequate PPE, and their ex post risk - that is, their risk of dying if they become infected - must also be reduced.

The strength of this claim may be challenged, however, by considering the scope of reciprocity as interpreted above. The argument for priority access for HCWs to limited treatment interventions claims that reciprocal return is owed for risks assumed in the course of benefiting others. But HCWs are not alone in fitting this description. Would our assumptions be as strong in the tiebreaker case if the choice were between an HCW and a supermarket worker who had also become infected in the course of her work providing an essential service for others? Possibly not. The problem with the priority argument, as it stands, is that it provides no principled way to prioritize HCWs over others who have assumed higher risks in order to provide an essential service. Yet those who advance this argument want reciprocity uniquely to pick out HCWs as recipients of the return, in part for feasibility reasons: the larger the group picked out by a priority principle the less effective it is.

It might be argued that priority as a reciprocal return is owed to HCWs, not only because of the increased risks they assume but because of the value of the benefits they provide. On this view, HCWs provide benefits that are more valuable, and less replaceable, than those of supermarket workers, bus drivers, and others exposed to increased risks in the course of their work. This argument implies that exposure to increased risk is not sufficient for priority access to limited treatment interventions; rather, exposure to increased risk and provision of highly valuable benefits are jointly necessary and sufficient. But the costs of this response are significant. Bioethicists and clinicians have spent decades developing fair and justifiable resource-allocation principles that do not depend on defining a person's social worth. Certainly there might be an instrumental argument for prioritizing HCWs if doing so ensured they would be available to help other patients. But this is not an argument grounded in reciprocity. To argue that there are reasons of reciprocity, and not just instrumental reasons, to prioritize HCWs because of the benefits they provide suggests that HCWs deserve priority because they are more valuable. When not grounded in the instrumental value of HCWs, this argument introduces the 'arbitrariness and bias' of determinations of people's relative value into priority-setting decisions (Rothstein 2010). 
Now it is possible to summarise the challenges for both PPE and priority access as reciprocal returns for HCWs. In the argument for PPE as a reciprocal return, the problem is that it is too narrow: as a return for fulfilling the duty to treat, the argument limits the obligation to HCWs, when the interpretation of reciprocity adopted implies that PPE would be a fitting and proportional return for all those who take on increased risks in the course of providing an essential public service. Conversely, the argument for priority access to ventilators and ICU beds as a reciprocal return is either too broad, suggesting priority should be given to all those who assume increased risk, or, if limited to HCWs by virtue of the benefits they provided, grounded in ethically dubious assessments of social worth.

These challenges might be met by switching the conditions for each argument. The scope of the argument for PPE will be broader if (a) assumption of increased risk and (b) provision of an essential service are considered jointly necessary and sufficient conditions for an obligation to provide PPE as a reciprocal return. The scope of the argument for priority access will be narrower if (a) assumption of increased risk and (c) acceptance of a duty to treat are jointly necessary and sufficient conditions to provide priority access to HCWs as a reciprocal return. This solution leaves intact the apparent moral intiution that HCWs should be given some priority for limited treatment interventions on grounds of reciprocity. There are costs to such a solution, however. First, in narrowing the scope of application, this solution no longer reflects the interpretation of the principle of reciprocity given above, according to which all those who provide benefits or services necessary for human well-being (that is, presumptive public goods) are owed reciprocal returns. Second, it is in tension with other allocation criteria considered important when making these prioritization decisions, such as maximizing benefits or saving the most lives (Wasserman, Persad, and Millum 2020). Third, there are significant practical complexities in applying this solution, such as determining which HCWs are eligible for prioritization and how much priority to give any particular HCW, taking into consideration different levels of risk exposure (Rothstein 2010; Persad, Wertheimer, and Emanuel 2009).

A final concern arises from the connection between these two candidates for reciprocal returns. It might be asked whether reciprocity requires reducing both ex ante and ex post risks encountered by HCWs in the course of fulfilling their duty to treat during a pandemic. Returning to the tiebreaker case can help answer this question. If the provision of PPE to the HCW in the tiebreaker is sufficient to have roughly equalised the risk exposure of the two people competing for the scarce good, then the non-HCW has a reasonable objection to losing their chance at that good. More definitively, if both candidates for the scarce good faced roughly the same ex ante risk (due to the provision of adequate PPE for HCWs), then exposure to increased risk no longer counts as a factor in favour of 
the HCW, and the necessary and sufficient conditions for priority access are no longer met. This argument suggests that some priority access for HCWs can be justified if, and only if, failure to provide adequate PPE means that the risks to which HCWs are exposed in the course of their work are meaningfully higher than for non-HCWs.

\section{Conclusion}

Fundamentally, reciprocity is a principle of fairness and grounds important obligations of justice. Where significant benefits from a presumptive public good are received, such as a functioning and accessible health-care system during a pandemic, fair return to those who provide the benefits is owed by beneficiaries. HCWs who provide those benefits, and assume higher levels of risk by doing so, are owed adequate PPE as a fair (fitting and proportional) return for their services. This is first and foremost an obligation of justice grounded in reciprocity. There is a strong intuition that priority for treatment is also a fair return for HCWs who become ill in the course of looking after others during a pandemic. The concept of reciprocity initially appears to support this intuition. Yet, as understood here, reciprocity does not straightforwardly justify giving HCWs priority for limited treatment interventions. Priority is neither a fitting nor a proportional return for services rendered, and it is in tension with other ethical commitments in the allocation of scarce resources, such as saving the most lives. The value of the benefits provided by HCWs might suggest instrumental reasons to prioritize HCWs for limited treatment interventions, but unless grounded in ethically dubious notions of social value, these are not reasons of justice. If deployment of adequate PPE roughly equalises the ex ante risks of HCWs and other candidates for the interventions, then reciprocity does not also demand, as a fair return, priority in the reduction of ex post risk.

\section{References}

Arneson, R. J. 1982. 'The Principle of Fairness and Free-Rider Problems', Ethics, 92: 616-33.

Arras, J. D. 1988. 'The Fragile Web of Responsibility: AIDS and the Duty to Treat', Hastings Center Report, 18: 10-20

Aulisio, M. P., and T. May. 2020. 'Why Healthcare Workers Ought to Be Prioritized in ASMR during the SARS-CoV-2 Pandemic', American Journal of Bioethics, 20: 125-28

Ballantyne, A., W. A. Rogers, V. Entwistle, and C. Towns. 2020. 'Revisiting the Equity Debate in COVID-19: ICU Is No Panacea', Journal of Medical Ethics, 46: 641-45

Becker, L. C. 1986. Reciprocity (London: Routledge and Kegan Paul) 
. 2005. 'Reciprocity, Justice, and Disability', Ethics 116: 9-39

Buchanan, A. 1990. 'Justice as Reciprocity versus Subject-Centered Justice', Philosophy and Public Affairs, 19: 227-52

Cox, C. L. 2020. " "Healthcare Heroes": Problems with Media Focus on Heroism from Healthcare Workers during the COVID-19 Pandemic', Journal of Medical Ethics, 46: 510-13

Dawson, A. 2016. 'Professional, Civic, and Personal Responsibilities in Public Health Emergency Planning and Response', in Emergency Ethics: Public Health Preparedness and Response, ed. by B. Jennings, J. D. Arras, D. H. Barrett, and B. A. Ellis (Oxford: Oxford University Press), pp. 186-219

Emanuel, E. J. 2003. 'The Lessons of SARS', Annals of Internal Medicine 139: 589-91

Emanuel, E. J., G. Persad, R. Upshur, B. Thome, M. Parker, A. Glickman, C. Zhang, C. Boyle, M. Smith, and J. P. Phillips. 2020. 'Fair Allocation of Scarce Medical Resources in the Time of Covid-19', New England Journal of Medicine, 382: 2049-55

Faulconer, A. W. 2020. 'Disambiguating Reciprocity: What Health Care Workers Are Due', American Society for Bioethics and Humanities Annual Conference (online)

Hart, H. L. A. 1955. 'Are There Any Natural Rights?' Philosophical Review, 64: 175-91

Jecker, N. S., A. G. Wightman, and D. S. Diekema. 2020. 'Prioritizing Frontline Workers during the COVID-19 Pandemic,' American Journal of Bioethics, 20: 128-32

Johnson, S. B., and F. Butcher. 2021. 'Doctors during the COVID-19 Pandemic: What Are Their Duties and What Is Owed to Them?' Journal of Medical Ethics, 47: 12-15

Klosko, G. 1987. 'Presumptive Benefit, Fairness, and Political Obligation.' Philosophy and Public Affairs 16(3):241-259

. 2020. 'Fair Play, Reciprocity, and Natural Duties of Justice', Ratio Juris, 33:335-50

Malm, H., T. May, L. P. Francis, S. B. Omer, D. A. Salmon, and R. Hood. 2008. 'Ethics, Pandemics, and the Duty to Treat,' American Journal of Bioethics, 8: 4-19

National Ethics Advisory Committee (NEAC). 2007. Getting Through Together: Ethical Values for a Pandemic (Wellington: Ministry of Health)

New York State Task Force on Life and the Law. 2015. Ventilator Allocation Guidelines (New York: New York State Department of Health)

Nozick, R. 1974. Anarchy, State, and Utopia (New York: Basic Books)

Persad, G., A. Wertheimer, and E. J. Emanuel. 2009. 'Principles for Allocation of Scarce Medical Interventions,' Lancet, 373: 423-31

Rawls, J. 1971. A Theory of Justice (Cambridge, MA: Harvard University Press)

Reid, L. 2005. 'Diminishing Returns? Risk and the Duty to Care in the SARS Epidemic,' Bioethics, 19: 348-61

Rothstein, M.A. 2010. 'Should Health Care Providers Get Treatment Priority in an Influenza Pandemic?' Journal of Law, Medicine E Ethics, 38: 412-19

Schmidtz, D. 2005. 'What We Deserve, and How We Reciprocate,' Journal of Ethics, 9: 435-64

Schuklenk, U. 2020. 'What Health Care Professionals Owe Us: Why their Duty to Treat during a Pandemic Is Contingent on Personal Protective Equipment (PPE),' Journal of Medical Ethics, 46: 432-35

White, D. B., and B. Lo. 2020. 'A Framework for Rationing Ventilators and Critical Care Beds during the COVID-19 Pandemic,' JAMA <http://dx.doi.org/10.1001/ jama.2020.5046> [accessed 19 June 2021]

Wasserman, D., G. Persad, and J. Millum. 2020. 'Setting Priorities Fairly in Response to Covid-19: Identifying Overlapping Consensus and Reasonable Disagreement,' Journal of Law and the Biosciences 7 <http://dx.doi.org/10.1093/jlb/lsaao44> [accessed 19 June 2021] 